\title{
PENGARUH PENERAPAN E-SYTEM PERPAJAKAN DAN TINGKAT PEMAHAMAN TERHADAP TINGKAT KEPUASAN WAJIB PAJAK PADA KPP PRATAMA MAKASSAR SELATAN
}

\author{
Suriani \\ (STIE Tri Dharma Nusantara) \\ Surianis43@yahoo.com
}

\begin{abstract}
ABSTRAK
Penelitian ini bertujuan untuk menguji apakah penerapan E-system perpajakan dan tingkat pemahaman wajib pajak pada Tingkat Kepuasan Wajib Pajak di KPP Pratama Makassar Selatan. Populasi dalam penelitian ini adalah wajib pajak pribadi di KPP Pratama Makassar Selatan. Metode pengambilan sampel yang digunakan dalam incidental sampling. Responden dalam penelitian ini adalah wajib pajak orang pribadi sebanyak 100 responden. Hipotesis diuji melalui analisis regresi linier berganda menggunakan SPSS (Paket Stastitical Untuk IImu Sosial) versi 22.0. Hasil penelitian ini Pengaruh Implementasi E-system Perpajakan dan Tingkat Kepuasan Pengertian Terhadap Tingkat Kepuasan Wajib Pajak.
\end{abstract}

Keywords: E-system of taxation, Understanding and Statisfaction taxpayer

\section{PENDAHULUAN}

Pajak merupakan salah satu sumber utama Anggaran Pendapatan Belanja Negara (APBN) terbesar. Peran penerima pajak saat ini sangat penting, dalam rangka pembangunan dan pemenuhan kebutuhan belanja Negara. Selain itu, pajak juga bertujuan untuk meningkatkan kesejahteraan rakyat melalui perbaikan dan penigkatan saran publik. Adanya peningkatan target terhadap penerimaan pajak ini mendorong Direktorat Jenderal Pajak (DJP) sebagai lembaga yang ditunjuk oleh pemerintah untuk menghimpun penerimaan pajak dengan berbagai upaya diantaranya melakukan reformasi perpajakan berupa penyempurnaan terhadap kebijakan perpajakan dan system administrasi perpajakan (modernisasi sistem administrasi perpajakan) sehingga potensi penerimaan pajak yang tersdia dapat dipungut secara optimal dan menjunjung asas keadilan sosial serta memberikan pelayanan prima kepada wajib pajak. 
Modernisasi administrasi perpajakan meliputi kebijakan reformasi administrasi dan reformasi pengawasan. Reformasi kebijakan terdiri dari amandemen undang-undang antara lain UU No. 36 tahun 2008 mengenai Pajak Penghasilan, UU No. 16 tahun 2009 mengenai Ketentuan Umum dan Tata Cara Perpajakan (KUP) , UU No. 42 tahun 2009 mengenai PPN dan PPNBM. Reformasi administrasi merupakan reformasi yang dilakukan berkaitan dengan organisasi, teknologi informasi dan SDM, sedangkan reformasi pengawasan terkait dengan adanya kode etik pegawai seirama dengan pelaksanaan good governance dan equal treatmment dapat berjalan dengan baik dengan demikian, tujuan dari modernisasi administrasi perpajakan diharapkan tercapainya tingkat kepuasan yang tinggi, kepatuhan yang tinggi, tingkat kepercayaan terhadap administrasi yang tinggi, dan tingkat produkifitas pegawai pajak yang tinggi sehingga penerimaan pajak akan meningkat.

Dalam kurun tahun 2015 sampai dengan 2017, Berikut ini adalah data wajib pajak orang pribadi yang tidak sebanding dengan pengguna e-filling pada KPP Pratama Makassar Selatan :

Tabel 1. Data jumlah wajib pajak dengan banding pengguna e-filling

\begin{tabular}{|c|c|c|c|}
\hline Wajib Pajak & Tahun & WP Terdaftar & $\begin{array}{c}\text { Jumlah pengguna } \\
\text { E-filling }\end{array}$ \\
\hline \multirow{3}{*}{ Orang Pribadi } & 2015 & 134.274 & 21.226 \\
\cline { 2 - 4 } & 2016 & 145.026 & 54.920 \\
\cline { 2 - 4 } & 2017 & 154.037 & 68.894 \\
\hline
\end{tabular}

Sumber : Pengolah Data dan Informasi KPP Pratama Makassar Selatan

Terdapat beberapa penelitian yang berkaitan dengan penerapan esistem dan tingkat kepuasan pengguna e-system. Penelitian yang dilakukan oleh Fitri Damayanti (2015) tentang Pengaruh Fasilitas Drop Box, E-SPT dan E-filling Dalam Penyampaian Surat Pemberitahuan (SPT) Terhadap Kepuasan Wajib Pajak .Dalam penelitianya menunjukkan bahwa Pengaruh Fasilitas Drop Box, E-SPT dan E-filling Dalam Penyampaian Surat Pemberitahuan (SPT) Terhadap Kepuasan Wajib Pajak memiliki pengaruh secara parsial terhadap kepuasan wajib pajak. 
Penelitian ini merupakan pengembangan dari penelitian yang pernah dilakukan Fitri Damayanti oleh Helen Widjaja (2017) tentang Analisis Penerapan E-system Perpajakan Pada Wajib Pajak Pribadi Terhadap Pelaksanaan Self Assesment System Dalam memenuhi Kewajiban Perpajakan Hasil penelitian ini menunjukkan bahwa fasilitas pelayanan yang diberikan oleh Direktorat Jenderal Pajak seperti Penerapan E-system Pada KPP Pratama Kebayoran Baru Tiga Jakarta Selatan Efektif dan Efisien dan telah memenuhi kewajiban perpajakan di KPP Pratama Kebayoran Baru Tiga Jakarta Selatan.

Berdasarkan uraian rumusan masalah di atas, tujuan penelitian ini sebagai berikut :

1. Untuk mengetahui apakah penerapan e-system berpengaruh terhadap kepuasan wajib pajak pada KPP pratama makassar selatan.

2. Untuk mengetahui apakah tingkat pemahaman berpengaruh terhadap kepuasan wajib pajak pada KPP pratama makassar selatan.

3. Untuk mengetahui apakah penerapan e-sytem dan tingkat pemahaman berpengaruh simultan terhadap kepuasan wajib pajak pada KPP pratama makassar selatan.

\section{TELAAH LITERATUR DAN PENGEMBANGAN HIPOTESIS Penerapan E-System Perpajakan}

Istilah penerapan dalam kamus besar bahasa Indonesia berarti proses, cara, dan perbuatan menerapkan. Penerapan juga diartikan sebagai pemasangan, pemanfaatan dan perihal mempraktikkan sesuatu. Definisi $e-$ system (system elektronik) pada dasarnya merupakan serangkaian perangkat dan prosedur yang berfungsi mempersiapkan, mengumpulkan, menganalisis, menyimpan, menampilkan, mengumumkan, mengirimkan dan menyebarkan informasi elektronik. Menurut Pujiani dan Efendi dalam (Novita 2012) dalam mendefinisikan e-system perpajak adalah sebagai berikut :

E-system perpajakan merupakan modernisasi perpajakan dengan menggunakan teknologi informasi yang diharapkan dengan e-system ini dapat mempermudah wajib pajak dalam melakukan kewajiban 
perpajakannya. Dapat dikatakan bahwa penerapan e-system dalam perpajakan adalah penerapan elektronis yang memberikan informasi mengenai kewajiban perpajakann baik wajib pajak pribadi maupun badan yang terdaftar agar dapat melakukan kewajibannya dengan mudah, lebih cepat dan efisien.

\section{Indikator E-system Perpajakan}

\section{1) E-Registrassion}

\section{Pengertian E-registrasion}

Setiap wajib pajak yang telah memenuhi persyaratan subjektif dan objektif sesuai dengan perundang-undangan perpajakan, wajib pajak mendaftarkan diri pada kantor Direktorat Jenderal pajak yang wilayah kerjanya meliputi tempat tinggal atau kedudukan wajib pajak ddan kepadanya diberikan NPWP, sebelum diterapakannya e-system perpajakan, pendaftaran NPWP dan pengukuhan Pengusaha Kena pajak (PKP) dilakukan secara manual, dan setelah adanya program modernisasi administrasi perpajakan makadapat dilakukan apluikasi e-registasion.

Berdasarkan Peraturan Direktorat Jenderal Pajak Nomor PER24/PJ/2009 pengetian E-Registrasion adalah System pendaftaran Wajib Pajak dan/atau pengukuhan pengusaha Kena Pajak dan/atau Pengusaha Kena Pajak melalui intenet yang terhubung langsung secara online dengan Direktorat Jenderal Pajak. Dengan demikian dapat disimpulkan bahwa E-Registrasion merupakan layanan yang disediakan oleh Direktorat Jenderal Pajak yang berupa sistem pendaftran wajib pajak dan atau pengukuhan pengusaha kena pajak dan perubahan datanya melalui internet yang terhubung langsung secara online dengan Direktorat Jenderal Pajak..

\section{2) $E-S P T$}

\section{a. Pengertian E-SPT}

Dalam mewujudkan system administrasi perpajakan yang modern, pemerintah menyediakan aplikasi yang dapat digunakan oleh masyarakat untuk melakukan pengisian dan pelaporan SPT secara cepat, tepat dan akurat. Aplikasi yang disediakan oleh direktorat jenderal Pajak untuk 
digunakan olleh wajib Pajak yaitu melaporkan pelaporan pajak dengan menggunakan elektronik SPT (e-SPT).

Menurut peraturan Direktur Jenderal Pajak Nomor -19/PJ/2009 menyatakan bahwa definisi elektronik SPT adalah sebagai berikut:..

\section{b. E-Filling}

\section{1) Pengertian E-Filling}

E-Filling adalah suatu cara penyampaian SPT atau penyampaian Pemberitahuan Perpanjangan SPT tahunan secara elektronik yang dilakukan secara online dan realtime melalui website Direktorat Jendereral Pajak atau penyedia jasa Aplication Service Provider $(A S P)$. Sehingga Wajib Pajak tidak perlu lagi melakukan percetakan semua formulir laporan dan menunggu tanda terima secara manual. Online berarti bahwa Wajib Pajak dapat melaporkan pajak melalui internet dimana saja dan kapan saja, sedangkan kata realtime berarti bahwa konfirmasi dari Direktorat jenderal Pajak (DJP) dapat diperoleh saat itu juga apabila data-data Surat Pemberitahuan (SPT) yang diisi lengkap dan benar telah sampai dikirim secara elektronik.

\section{Pengertian Tingkat Pemahaman Perpajakan}

Tingkat Pemahaman Perpajakan adalah tingkatan pengetahuan dan pikiran Wajib Pajak atas kewajiban perpajakannya untuk memberikan kontribusi kepada Negara dalam memenuhi keperluan pembiayaan dan pembangunan nasional guna tercapainya keadilan dan kemakmuran.

\section{a. Indikator Tingkat Pemahaman Perpajakan}

Indikator tingkat pemahaman perpajakan yang digunakan dalam penelitian ini adalah pengetahuan perpajakan sesuai dengan ketentuan umum perpajakan :

1) Sosialisasi Perajakan

Menurut Oktaviane (2013:962) Sosialisasi perpajakan merupakan suatu langkah yang dapat diitempuh oleh DJP untuk memberikan penyuluhan kepada masyarakat dimakudkan untuk memberi pengertian kepada masyarakat tentang modernisasi 
perpajakan dan pentingnya membayar pajak. dengan sosialisasi ini masyarakat menjadi mengerti dan paham tentang manfaat membayar pajak serta sanksi jika tidak membayar pajak.

2) Pelayanan Fiskus

Pelayanan fiskus yaitu segala kegiatan upayah yang dilakukan oleh DJP untuk memberikan pelayanan prima kepada wajib pajak dalam mengoptimalkan penrimaan negara ( Rahayu 2017 :464).

3) Pengetahuan Perpajakan

Pengetahuan pajak adalah informasi pajak yang dapat digunakan wajib pajak sebagai dasar untuk bertindak, mengambil keputusan, dan untuk menempuh arah atau strategi tertentu sehubungan dengan pelaksanaan hak dan kewajibannya di bidak perpajakan.

\section{Kepuasan Wajib Pajak}

Menurut Fandy Tjipto ( Darmawanto 2009 ) yang mengutip pendapat Day (dalam Tse dan Wilton) menjelaskan bahwa : Kepuasan atau ketidakpuasan pelanggan adalah respon pelanggan terhadap evaluasi ketidaksesuaian (disconfirmation yang di rasakan antara harapan sebelumya (atau norma kinerja lainnya) dan kinerja aktual produk yang dirasakan setelah pemakaiannya.

Sedangkan menurut Philip Kotler dalam Veronica (2010) menyatakan bahwa definis ketidakpuasan sebagai berikut : Artinya kepuasan pelanggan adalah perasaan senang atau kecewa seseorang sebagai hasil dari perbandingan antara prestasi atau produk yang dirasakan dan yang diharapkan.

\section{Kerangka Konseptual}

Kerangka Konseptual Penelitian adalah suatu atau kaitan antara konsep satu terhadap konsep yang lainya dari masalah yang ingin diteliti, seperti hubungan Penerapan E-sistem Perpajakandan Tingkat Pengetahuan terhadap variabel terkait Tingkat Kepuasan Wajib Pajak. Tingkat Pemahaman Perpajakan adalah tingkatan pengetahuan dan pikiran Wajib 
Pajak atas kewajiban perpajakannya untuk memberikan kontribusi kepada Negara dalam memenuhi keperluan pembiayan dan pembangunan nasional guna tercapainya keadilan dan kemakmuran. Indikatornya adalah sosialisasi perpajakan.

Kepuasan Wajib Pajak adalah respon berupa perasaan senang atau kecewa terhadap evaluasi dari perbandingan antara harapan sebelumnya dengan sesuatu yang dirasakan setelah pemakaian. Kepuasan wajib pajak dapat ditinjau dari wajib pajak yaitu mengenai apa yang dirasakan atas pelayanan yang telah di terima dibandingkan dengan apa yang merka inginkan. Indikatornya adalah Tangibles (bukti langsung), Reliability (keandalan), Responsiveness (daya tanggap), Assurance (jaminan) dan Emphaty (empati)

Berikut merupakan skema kerangka konseptual penelitian :

Gambar 1

Kerangka konseptual penelitian

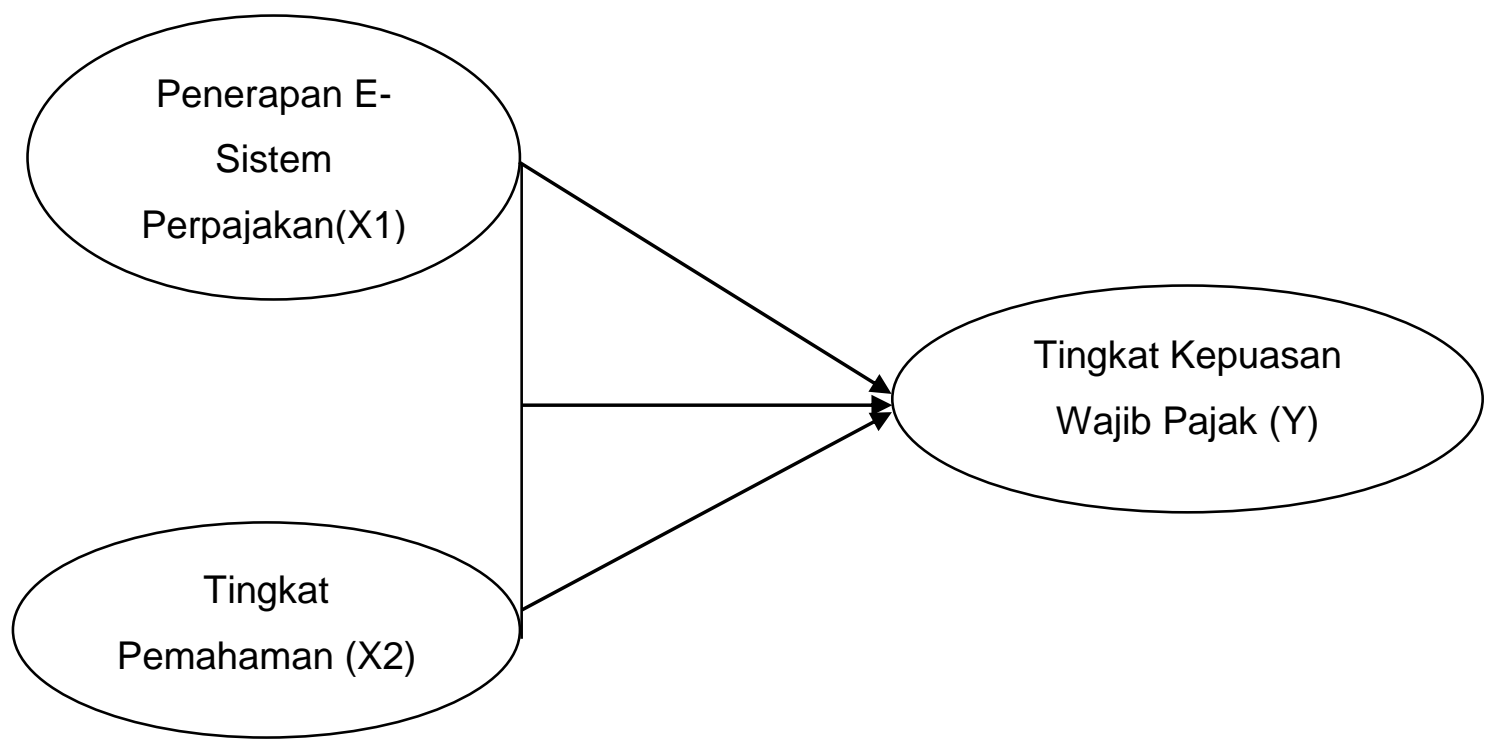

\section{III.METODOLOGI PENELITIAN}

\section{Populasi dan Sampel}

\section{Populasi}

Populasi adalah wilayah generalisasi yang terdiri atas obyek/subjek yang mempunyai kuantitas dan karakteristik tertentu yang ditetapkan oleh 
peneliti untuk dipelajari dan kemudian ditarik kesimpulannya. (Sugiyono 2017 :61). Populasi yang akan dijadikan objek penelitian ini adalah Wajib Pajak Orang Pribadi yang terdaftar di Kantor Pelayanan Pajak Makassar Selatan. Jumlah populasi dalam penelitian ini yaitu 59.179 Wajib Pajak Orang Pribadi (KPP pratama makassar selatan, 2015)

\section{Sampel}

Dalam sebuah penelitian tidak semua populasi dapat diteliti karena beberapa faktor diantaranya karena keterbatasan dana, tenaga, waktu dan keterbatasan fasilitas lain yang mendukung penelitian. Menurut (Sugiyono 2017 : 62 ) sampel adalah bagian dari jumlah dan karakteristik yang dimiliki oleh populasi.

\section{HASIL PENELITIAN DAN PEMBAHASAN}

\section{Analisis Statistik Inferensial}

Tabel 2 : Koefisien regresi

\begin{tabular}{|c|c|c|c|c|c|c|}
\hline \multicolumn{7}{|c|}{ Coefficients $^{a}$} \\
\hline \multirow{2}{*}{\multicolumn{2}{|c|}{ Model }} & \multicolumn{2}{|c|}{ Unstandardized Coefficients } & \multirow{2}{*}{$\begin{array}{c}\text { Standardized } \\
\text { Coefficients } \\
\text { Beta }\end{array}$} & \multirow[b]{2}{*}{$t$} & \multirow[b]{2}{*}{ Sig. } \\
\hline & & $\mathrm{B}$ & Std. Error & & & \\
\hline & (Constant) & 1,295 & 5,591 & & ,232 & ,817 \\
\hline & $\mathrm{X} 1$ & ,491 & ,098 & ,416 & 5,019 &, 000 \\
\hline & $\mathrm{X} 2$ &, 508 &, 117 & ,360 & 4,336 &, 000 \\
\hline
\end{tabular}

a. Dependent Variable: $Y$

Berdasarkan tabel koefisien regresi diatas, maka dapat dibuat suatu persamaan regresi sebagai berikut:

$$
Y=1,295+0,491 X 1+0,508 \times 2
$$

\section{Uji Parsial (T-test)}

Hasil uji parsial (uji t) dapat dilihat pada tabel dibawah ini :

Tabel 3 : Uji Parsial T

\begin{tabular}{|ll|r|r|}
\hline & & & \multicolumn{1}{|c|}{} \\
Model & & \multicolumn{1}{|c|}{ T } & \multicolumn{1}{c|}{ Sig. } \\
\hline 1 & (Constant) &, 232 &, 817 \\
& PENERAPAN E-SYTEM & 5,019 &, 000 \\
& TINGKAT PEMAHAMAN & 4,336 &, 000 \\
\hline
\end{tabular}




\section{Uji Simultan (F-Test)}

Uji $F$ digunakan untuk mengetahui apakah variabel independen secara simultan atau secara bersama-sama memiliki pengaruh terhadap variabel dependen. Kriteria pada pengujian simultan (uji F) ini adalah jika $F_{\text {hitung }}>F_{\text {tabel }}$ dan tingkat signifikan $<0,05(5 \%)$ maka dapat dinyatakan bahwa $\mathrm{H}_{\mathrm{a}}$ diterima dan $\mathrm{H}_{\mathrm{o}}$ ditolak (Syahruddin dkk. 2015). Hasil statistik uji $\mathrm{F}$ diperoleh melalui tabel Analyisis of varian (Anova) yaitu:

Tabel 4. : Uji Simultan F

\begin{tabular}{|c|c|c|c|c|c|c|}
\hline \multicolumn{7}{|c|}{ ANOVA $^{a}$} \\
\hline & & Sum of Squares & Df & Mean Square & $\mathrm{F}$ & Sig. \\
\hline \multirow[t]{3}{*}{1} & Regression & 906,257 & 2 & 453,129 & 31,678 &, $000^{b}$ \\
\hline & Residual & 1387,503 & 97 & 14,304 & & \\
\hline & Total & 2293,760 & 99 & & & \\
\hline
\end{tabular}

a. Dependent Variable: $Y$

b. Predictors: (Constant), X2, X1

Sumber : Data Primer diolah SPSS V.22, 2017

\section{Uji Determinasi $\left(\mathbf{R}^{2}\right)$}

Ghozali (2013) mengatakan koefisien determinasi bertujuan untuk mengukur seberapa jauh kemampuan model dapat menjelaskan variasi variabel dependen. Dalam pengujian hipotesis koefisien determinasi dilihat dari besarnya niai $\mathrm{R}$ Square $\left(R^{2}\right)$, untuk mengetahui seberapa jauh variabel bebas "pengaruh e-system perpajakan dan tingkat pemahaman terhadap tingkat kepuasan wajib pajak". Adapun hasil uji determinasi yaitu:

Tabel 5 Uji Determinasi $\left(R^{2}\right)$

\begin{tabular}{|l|r|r|r|r|}
\hline Model & R & R Square & Adjusted R Square & $\begin{array}{c}\text { Std. Error of the } \\
\text { Estimate }\end{array}$ \\
\hline 1 &, $629^{\mathrm{a}}$ &, 395 &, 383 & 3,782 \\
\hline
\end{tabular}
a. Predictors: (Constant), X2, X1
b. Dependent Variable: $Y$ 


\section{Pengaruh Penerapan E-system Perpajakan $\left(\mathrm{X}_{1}\right)$ Terhadap Kepuasan WP} (Y)

Berdasarkan analisis data dari hasil pengujian hipotesis diperoleh hasil regresi berganda pada penelitian ini bahwa penerapan e-sytem perpajakan berpengaruh positif dan signifikan terhadap tingkat kepuasan wajib pajak. Dapat dilihat dari nilai koefisien regresi bernilai positif sebesar 0,491 dan didukung dengan nilai $T_{\text {hit. }}$ sebesar 5,019 lebih besar dari nilai $T_{\text {tab. yaitu }}$ 1,660 serta diperkuat dengan nilai signifikan lebih kecil dari $0,05(0,05>$ 0.000). Hal ini menunjukkan bahwa hipotesis $H_{1}$ diterima yang berarti penerapan e-system perpajakan berpengaruh positif dan signifikan terhadap tingkat kepuasan wajib pajak pada Kantor Pelayanan Pajak Makassar Selatan.

Selain itu, nilai rata-rata penerapan e-system perpajakan sebesar 4,11 , hal ini menandakan bahwa wajib pajak pada KPP Makassar Selatan setuju bahwa untuk meningkatkan kepuasan wajib pajak maka diperlukan penerapan e-system untuk memudahkan pelaporan perpajakan. Artinya dengan penerapan e-system yang semakin baik maka semakin meningkat pula kepuasan wajib pajak pada KPP Makassar Selatan. Penerapan esystem yang merupakan sistem elektronis yang memberikan informasi mengenai kewajiban perpajakan baik wajib pajak yang terdaftar agar dapat melakukan kewajibannya dengan mudah, lebih cepat dan efisien.

Hasil penelitian ini mendukung hasil penelitian Fitri Damayanti (2015) yang menemukan bahwa pengaruh fasilitas dropbox, e-spt, dan e,filling berpengaruh positif terhadap kepuasan wajib pajak. Hal ini menyatakan bahwa semakin baik penerapan e-sytem perpajakan maka kepuasan wajib pajak semakin meningkat.

\section{Pengaruh Tingkat Pemahaman $\left(\mathrm{X}_{2}\right)$ TerhadapTingkat Kepuasan WP (Y)}

Berdasarkan analisis data dari hasil pengujian hipotesis diperoleh hasil regresi berganda pada penelitian ini bahwa tingkat pemahaman wajib pajak berpengaruh positif dan signifikan terhadap tingkat kepuasan wajib pajak. Dapat dilihat dari nilai koefisien regresi sanksi pajak bernilai positif sebesar 0,508 dan didukung dengan nilai t hitung sebesar 4,336 lebih besar dari nilai 
t tabel yaitu 1,660 serta diperkuat dengan nilai signifikan lebih kecil dari 0,05 $(0,05>0,000)$. Artinya semakin tinggi tingkat pemahaman wajib pajak maka kepuasan wajib pajak semakin tinggi. Hal ini menunjukkan bahwa hipotesis $\mathrm{H}_{2}$ diterima yang berarti tingkat pemahaman berpengaruh positif dan signifikan terhadap kepuasan wajib pajak pada Kantor Pelayanan Pajak Makassar Selatan.

Selain itu, nilai rata-rata tingkat pemahaman sebesar 13,23, hal ini menandakan bahwa wajib pajak pada KPP Makassar Selatan setuju bahwa untuk meningkatkan kepuasan wajib pajak maka diperlukan tinggat pemahaman wajib pajak yang tinggi.

Pengaruh Penerapan E-Sytem Perpajakan $\left(\mathrm{X}_{1}\right)$ dan Tingkat Pemahaman $\left(\mathrm{X}_{2}\right)$ Terhadap Kepuasan Wajib Pajak (Y)

Berdasarkan analisis data dari hasil pengujian hipotesis diperoleh hasil regresi berganda pada penelitian ini dapat dilihat nilai $F_{\text {hitung. }}$ sebesar 31,678 lebih besar dari nilai $F_{\text {tabel. }}$ yaitu 3,090 serta diperkuat pada tingkat signifikan 0,000 atau nilai signifikan lebih kecil dari $0,05(0,05>0,000)$. Nilai $F_{\text {hit. }}>F_{\text {tab. }}$ menandakan bahwa terdapat pengaruh penerapan e-system perpajakan dan tingkat pemahama perpajakan secara positif dan signifikan terhadap kepuasan wajib pajak.

Hasil penelitian ini menunjukkan hubungan positif dan signifikan yang berarti bahwa dengan penerapan e-system perpajakan dan tingkat pemahaman perpajakan tinggi maka dapat mendorong meningkatkanya kepuasan wajib pajak pada Kantor Pelayanan Pajak Makassar Selatan. Hal ini menunjukkan bahwa hipotesis $\mathrm{H}_{3}$ diterima yang berarti penerapan $e$ sytem perpajakaan dan tingkat pemahaman perpajakan berpengaruh positif dan signifikan terhadap kepatuhan wajib pajak pada Kantor Pelayanan Pajak Makassar Selatan.

Hal ini sejalan dengan pendapat yang dikemukakan oleh Pandiangan (2017) yang menyatakan bahwa reformasi perpajakan merupakan kebijakan dalam melakukan perbaikan aturan dan pelaksanaan aturan guna mencapai sasaran menuju sistem perpajakan yang lebih baik.

Selain itu, nilai rata-rata kepuasan wajib pajak sebesar 3,80 ini 
menandakan bahwa wajib pajak pada Kantor Pelayanan Pajak Makassar Selatan termasuk dalam kriteria cukup puas dalam melaksanakan kewajibannya dan nilai $R$ square sebesar 0,395 atau 39,05\% yang berarti besarnya pengaruh variabel independen (penerapan e-sytem perpajakan dan tingkat pemahaman perpajakan) terhadap variabel dependen (kepuasan wajib pajak) dan sisanya $61,95 \%$ dipengaruhi oleh variabel lain diluar model penelitian ini.

\section{KESIMPULAN}

\section{Kesimpulan}

Berdasarkan hasil penelitian dan pembahasan maka dapat disimpulkan sebagai berikut::

1. Penerapan e-system perpajakaan berpengaruh positif dan signifikan terhadap kepuasan waji pajak pada Kantor Pelayanan Pajak Makassar Selatan. Artinya semakin meningkat penerapan e-sytem perpajakan yang dilakukan maka akan meningkatkan kepuasan wajib pajak pada Kantor Pelayanan Pajak Makassar Selatan.

2. Tingkat pemahaman perpajakan berpengaruh positif dan signifikan terhadap tingkat kepuasan wajib pajak pada Kantor Pelayanan Pajak Makassar Selatan. Artinya semakin tinggi tingkat pemahaman wajib pajak maka semakin tinggi pula tingkat kepuasan wajib pajak pada Kantor Pelayanan Pajak Makassar Selatan.

3. Penerapan e-system perpajakan dan tingkat pemahaman perpajakan berpengaruh positif dan signifikan terhadap tingkat kepuasan wajib pajak pada Kantor Pelayanan Pajak Makassar Selatan. Hal ini menerangkan bahwa semakin banyak sosialisai yang dilakukan oleh kantor pajak maka dapat mendorong tingkat pemahaman wajib pajak dan tingkat kepuasan wajib pajak juga akan meningkat.

\section{Saran}

Berdasarkan pada penelitian yang telah dilakukan dan hasil kesimpulan yang diperoleh, maka saran yang diajukan dalam penelitian ini adalah:: 
1. Kantor Pelayanan Pajak Makassar Selatan untuk lebih mengoptimalkan sosialisai penggunaan e-system karna masih banyak wajib pajak yang belum mengetahui kemudahan melaporkan dan membayar dengan menggunakan e-sytem perpajakan, sehingga wajib pajak lebih mengetahui fungsi, manfaat dan cara melaporkan kewajiban perpajakannya dengan menggunakan aplikasi yang berbasis e-system. Selain itu kualitas pelayanan juga perlu ditingkatkan agara kepuasan wajib pajak akan semakin meningkat

2. Kantor Pelayanan Pajak Makassar Selatan untuk semakin mengembangkan ilmu pengetahuan akuntansi khususnya bidang perpajakan yang erat kaitannya dengan tingkat kepuasan wajib pajak.

3. Peneliti selanjutnya, menambah variabel independen, yang diteliti dalam penelitian ini yang mempengaruhi tingkat kepuasan wajib pajak. Misalnya kualitas pelayanan

\section{DAFTAR PUSTAKA}

Agustiningsih, Wulandari (2016). Pengaruh Penerapan E-Filing, Tingkat Pemahaman Perpajakan Dan Kesadaran Wajib Pajak Terhadap Kepatuhan Wajib Pajak Di Kpp Pratama Yogyakarta. Jurnal Nominal. 5 (2) : 107-122.

Akdon, Riduwan. (2008). Rumus Dan Data Dalam Analisis Statistika. Bandung: Alfabeta.

Asbar, Akromi Kahirina. (2014). Pengaruh Tingkat Kepuasan Pelayanan, Pemahaman Perpajakan, Keadilan Perpajakan, Sanksi Perpajakan Dan Kesadaran Perpajakan Terhadap Tingkat Kepatuhan Wajib Pajak Orang Pribadi Pada KPP Pratama Senapelan Pekanbaru. Jom Fekon. $1(2): 1-15$.

Butarbutar, Rusal. (2017). Hukum Pajak Indonesia Dan Internasional. Bekasi :Gramata Publishing.

Damayanti, Fitri (2015). Pengaruh Fasilitas Dropbox, E-Spt, Dan E-Filling Dalam Penyampaian Surat Pemberitahuan (SPT) Terhadap Kepuasan Wajib Pajak. Akuntabilitas. 8 (3) : 226-237.

Eferin, Sujoko dkk. (2008). Metode Penelitian Akuntansi : Mengungkap Fenomena Dengan Pendekatan Kuantitatif Dan Kualitatif. Yogyakarta: Graha Ilmu. 
Hidayat Nurdin Dan Dedi Purwana. (2017). Perpajakan Teori Dan Praktik. Jakarta :Rajawali Pers/Raja Grafindo.

Ghozali, Imam (2012). Aplikasi Analisis Multivariate Dengan Program iBM SPSS. Yogyakarta :Universitas Diponegoro.

Kamus Besar Bahasa Indonesia. (2008). Jakarta :Balai Pustaka.

Khotler, Philip. 2010. Manajemen Pemasaran. Edisi Tida Belas Bahasa Indonesia. Jilid 1 dan 2. Jakarta : Erlangga.

Pandiangan, Liberti (2008). Modernisasi Dan Reformasi Pelayanan Perpajakan. Jakarta : PT Elex Media Komputindo.

Pandiangan, Liberti (2017). Administrasi Perpajakan :Pedoman Praktis Bagi Wajib Pajak Di Inodonesia. Jakarta :Erlangga.

Pohan, Chairil Anwar. (2017). Pembahasan Komprehensif Perpajakan Indonesia :Teori Dan Kasus. Edisi 2. Jakarta :Mitra Wacana Media.

Pujiani, Effendy dkk. (2012) Analisis Efektivitas Penggunaan E-Sistem Terhadap Penerimaan Pajak Di KPP Pratama Palembang Hllir Timur. Laporan Penelitian. Palembang :Sekolah Tinggi Ilmu Ekonomi Palembang.

Rahayu, Siti Kurnia. (2017). Perpajakan : Konsep dan Aspek Formal. Bandung : Rekayasa Sains.

Resmi, Siti. (2016). Perpajakan :Teori Dan Kasus. Edisi 9. Jakarta :SalembaEmpat.

Sari , Viega Ayu (2017). Pengaruh Tax Amnesty, Pengetahuan Perpajakan Dan Pelayanan Fiskus Terhadap Kepatuhan Wajib Pajak. Jurnal Dan Ilmu Riset Akuntansi. 6 (2) : 745-760.

Sari, Lydia Puspita (2015). Pengaruh Kesadaran Wajib Pajak, Tingkat Pemahaman Wajib Pajak Dan Sanksi Pajak Terhadap Kepatuhan Wajib Pajak. Jurnal Fekon. 2 (2) : 1-15.

Sekaran, Uma. (2009). Research Methods Of Business :Metodologi Penelitian Untuk Bisnis.Edisi 4. Bukun 1. Jakarta :Salemba Empat.

Sugiharti, Mirza Ayu. (2015). Analisa Efektifitas Kelayakan System Pelaporan Pajak Menggunakan E-Filling Terhadap Kepuasan Wajib Pajak. Jurnal Perpajakan. 6 (2) : 1-10.

Sugiyono. (2008). Metode Penelitian Analisis Keeratan Hubungan Antar Variabel. Bandung :Alfabeta.

Sugiyono. (2017). Statistika Untuk Penelitian.Bandung :Alfabeta. 
Supranto, J. (2011). Pengukuran Tingkat Kepuasan Pelanggan. Jakarta: Rineka Cipta

Syahruddin, Herman, Dkk. (2015). Laboratorium Pengolahan Data.

Tjiptono, Fandy. (2009). Strategi Pemasaran. Edisi 2. Cetakan Ke 7. Yogyakarta :Andi Offiset.

Undang Undang Nomor 1 Tahun 2009 Tentang Ketentuan Umum Dan Tata Cara Perpajakan.

Widjaja, Helen Dan Artus Jaya. (2017). Analisis Penerapan E-System Perpajakan Pada Wajib Pajak Orang PribadiTerhadap Pelaksanaan Self- Assessment System Dalam Memenuhi Kewajiban Perpajakan. Jurnal Ekonomi. 22 (3) : 440-447.

Widoyoko, EkoPutro. (2012). Teknik Penyusunan Instrument Penelitian. Yogyakarta : Pustaka Pelajar.

Winerungan Oktaviane Lydia. (2013). Sosialisasi Perpajakan, Pelayanan Fiskus Dan Sanksi Perpajakan Terhadap Keptuhan Wajib Pajak WPOP Di KPP Manado Dan KPP Bitung. Jurnal Emba. 1 (3) : 960-970. 